J. Dairy Sci. 98:6856-6864

http://dx.doi.org/10.3168/jds.2014-9129

(c) 2015, THE AUTHORS. Published by FASS and Elsevier Inc. on behalf

of the American Dairy Science Association ${ }^{\circledR}$. This is an open access article under

the CC BY-NC-ND license (http://creativecommons.org/licenses/by-nc-nd/3.0/).

\title{
Randomized clinical trial of intrauterine cephapirin infusion in dairy cows for the treatment of purulent vaginal discharge and cytological endometritis
}

\author{
J. Denis-Robichaud ${ }^{1}$ and J. Dubuc ${ }^{2}$ \\ Faculté de médecine vétérinaire, Université de Montréal, C.P. 5000, Saint-Hyacinthe, Québec, J2S 7C6, Canada
}

\begin{abstract}
The objectives of this study were to quantify the effect of an intrauterine infusion of cephapirin on reproductive performance at first service of postpartum dairy cows affected by purulent vaginal discharge (PVD) and cytological endometritis (ENDO) using different diagnostic strategies, and to determine if the presence of prolonged anovulation would influence the magnitude of treatment benefit. In total, 2,259 Holstein cows in 28 herds were enrolled in a randomized clinical trial. At $35( \pm 7)$ days in milk (DIM), cows were diagnosed with PVD using the Metricheck device (Simcro, Hamilton, New Zealand), with cytological endometritis using endometrial cytology (ENDO-CYTO), and with cytological endometritis using leukocyte esterase (ENDO-LE). Regardless of reproductive tract disease status, cows were randomly assigned to receive an intrauterine cephapirin infusion or to not be treated. Serum progesterone was measured at 35 and $49( \pm 7)$ DIM (14 d apart); cows were considered to have prolonged anovulation if progesterone was $<1 \mathrm{ng} / \mathrm{mL}$ at both times. Reproductive events of cows were collected until 200 DIM. Statistical analyses were conducted using multivariable mixed logistic regression models. Intrauterine cephapirin treatment was associated with an increased firstservice pregnancy risk in cows diagnosed with PVD (no treatment: 15.4\%; treatment: $31.4 \%$ ), ENDO-CYTO (no treatment: 16.2\%, treatment: $24.4 \%$ ), and ENDOLE (no treatment: $15.8 \%$; treatment: $25.1 \%$ ), but not in cows unaffected by any form of reproductive tract disease (no treatment: $34.8 \%$; treatment: $32.6 \%$ ). Cephapirin treatment was also associated with an increased first-service reproductive performance in cows affected simultaneously by both PVD and ENDO-CYTO (no
\end{abstract}

Received November 19, 2014

Accepted June 8, 2015.

${ }^{1}$ Current address: Department of Population Medicine, University of Guelph, Guelph, Ontario, N1G 2W1, Canada.

${ }^{2}$ Corresponding author: Jocelyn.dubuc@umontreal.ca treatment: $8.7 \%$; treatment: $23.4 \%$ ). The effect of cephapirin treatment in anovular cows (no treatment: $21.0 \%$; treatment: $26.4 \%$ ) was numerically lower than in cyclic cows (no treatment: $22.7 \%$; treatment: $34.1 \%$ ). Overall, an intrauterine infusion of cephapirin improved first-service pregnancy risk in cows with postpartum reproductive tract disease and this effect was influenced by postpartum anovulation status.

Key words: dairy cow, treatment, endometritis, cephapirin

\section{INTRODUCTION}

Purulent vaginal discharge (PVD) and cytological endometritis (ENDO) are associated with impaired subsequent reproductive performance in postpartum dairy cows (LeBlanc et al., 2002a; Gilbert et al., 2005; Dubuc et al., 2010). The use of an intrauterine infusion of cephapirin is approved in Canada (Merck Animal Health, Montréal, Canada) and other countries for the treatment of PVD. Intrauterine cephapirin infusion has been shown by multiple studies to improve reproductive performance of dairy cows with PVD (LeBlanc et al., 2002b; Runciman et al., 2008), but little data are available for cows with ENDO (Kasimanickam et al., 2005). Interestingly, no studies have diagnosed and simultaneously reported PVD and ENDO when investigating the efficacy of an intrauterine cephapirin infusion. Using such an approach could provide more insight into the benefit of performing reproductive tract disease surveillance in dairy herds and on the benefit of treating affected cows.

Reproductive tract disease diagnostic tools such as the Metricheck (Simcro, Hamilton, New Zealand; McDougall et al., 2007; Dubuc et al., 2010), vaginoscope (LeBlanc et al., 2002a; Runciman et al., 2009), endometrial cytobrush (Kasimanickam et al., 2004; Dubuc et al., 2010), and endometrial leukocyte esterase (LE; Cheong et al., 2012; Couto et al., 2013) tests have been shown to be useful for the identification of cows with poorer subsequent reproductive performance. However, 
most of these studies evaluated only the association between one form of disease (PVD or ENDO) and subsequent reproductive performance. A recent study determined that the best pair of diagnostic criteria when using the Metricheck and cytobrush techniques simultaneously was $\geq 4$ (purulent or worse vaginal discharge; PVD) and $\geq 6 \%$ polymorphonuclear cells (ENDO-CYTO), respectively (Denis-Robichaud and Dubuc, 2015). Similarly, in the same report, the optimal pair of diagnostic criteria when using the Metricheck and leukocyte esterase techniques was $\geq 4$ (purulent or worse vaginal discharge; PVD) and $\geq 1$ (small amounts of leukocytes; ENDO-LE), respectively. The diagnostic performance of using these tests was reported, but it remains unclear at this time whether a treatment with intrauterine cephapirin infusion of cows diagnosed with PVD, ENDO-CYTO, or ENDO-LE using these strategies would improve their subsequent reproductive performance.

Although the use of intrauterine cephapirin therapy has been shown to be beneficial for cows with PVD (LeBlanc et al., 2002b; Runciman et al., 2008), only one study has investigated the effect of having or not a corpus luteum at the time of infusion (as a proxy for identification of anovular cows; LeBlanc et al., 2002b). It seems intuitive that the positive effect of cephapirin treatment on cows affected by PVD, ENDO-CYTO, or ENDO-LE may be modulated by ovulatory status. Prolonged postpartum anovulation has been associated with poorer reproductive performance (Walsh et al., 2007; Galvão et al., 2010; Dubuc et al., 2012) and the positive effect of intrauterine cephapirin in these cows could be influenced by it. A recent study reported that prolonged anovulation and cytological endometritis have additive detrimental effects on subsequent reproductive performance of cows (Vieira-Neto et al., 2014). Unfortunately, it remains unclear whether the presence of prolonged anovulation reduces the benefit of cephapirin intrauterine infusion in cows with PVD or ENDO.

Therefore, the first objective of this study was to quantify the effect of an intrauterine infusion of cephapirin on reproductive performance at first service in postpartum dairy cows affected by PVD, ENDOCYTO, or ENDO-LE. The second objective was to determine if the presence of a prolonged anovulation period would influence the magnitude of the benefit from intrauterine cephapirin therapy.

\section{MATERIALS AND METHODS}

Holstein cows from 28 commercial dairy herds were enrolled in a randomized clinical trial conducted between October 2011 and December 2013 (26 herds were enrolled in the first year and 2 were enrolled in the second year of farm data collection). Herds were selected by convenience based on being within a $250-\mathrm{km}$ radius of St-Hyacinthe (Québec, Canada), on having a computerized record system, and on using an ovulation synchronization protocol (Double-Ovsynch or Presynch-Ovsynch; systematic use of the same protocol within herd) to synchronize the first service of all cows around 70 DIM. Herd size ranged from 40 to 600 cows with a median of 91 cows. In total, 22 herds were housed in tiestall barns and 6 herds were housed in freestall barns (milking parlor). All cows that calved in these herds during the study period and that were bred at least once before 100 DIM were enrolled in the trial. Reproductive performance of these cows was recorded until 200 DIM. All herds used exclusively AI for breeding. Pregnancy diagnosis was performed by transrectal palpation between 33 and $47 \mathrm{~d}$ after insemination. Each cow could only be enrolled once in the study. The estimated sample size needed for this study was 2,344 cows. This sample size was planned to identify a difference of $10 \%$ in pregnancy risk at first service between treated (30\%) and untreated (20\%) cows with $95 \%$ confidence and $80 \%$ power (Dohoo et al., 2009) when expecting a disease prevalence of $25 \%$.

Farms were visited biweekly (every $14 \mathrm{~d}$ ) by an animal health technician and a veterinarian. Cows were examined for PVD, ENDO-CYTO, and ENDO-LE at $35( \pm 7)$ DIM. Purulent vaginal discharge was diagnosed first using vaginal discharge score assessed with the Metricheck device $(0=$ no discharge, $1=$ clear mucus, $2=$ mucus with flecks of pus, $3=$ mucopurulent discharge, $4=$ purulent discharge or $5=$ foul smelling discharge; McDougall et al., 2007). Diagnostic of ENDO-CYTO was done using a cytobrush technique (endometrial cytology) adapted for use in cattle (Kasimanickam et al., 2004; Dubuc et al., 2010) and diagnostic of ENDO-LE was done using an LE technique (Couto et al., 2013). Immediately after collection, the cytobrush was rolled on a microscope glass slide to obtain a smear. After that, the cytobrush was placed in an individual $3-\mathrm{mL}$ glass vial containing $1 \mathrm{~mL}$ of $0.9 \%$ saline $(\mathrm{NaCl} 0.9 \%$ Irrigation, Baxter Corp., Mississauga, ON, Canada). The microscope slides were stained within $12 \mathrm{~h}$ of collection with a modified Wright-Giemsa stain (Hema3; Biochemical Sciences, Swedesboro, NJ) and glass coverslips were applied when dry as previously described (Dubuc et al., 2010). The percentage of PMNL on these slides was determined using a microscope $(400 \times$ magnification) and slides were read by 2 observers (an animal health technician and a veterinarian). Two hundred cells (PMNL and endometrial cells) were counted on each slide. Slide readers were blinded to on-farm findings and treatment allocation. Within $12 \mathrm{~h}$ of collection, the individual vial containing the cytobrush was shaken for $10 \mathrm{~s}$ and a 
drop of the solution was put on a commercial LE test strip (Multistix 10 SG; Bayer Corporation, Elkart, IN) using a pipette. Because of material availability, LE testing only began in December 2011 even though farm visits started in November 2011. The LE strip results of every cow were read after 2 min according to the manufacturer's colorimetric chart, and the score was recorded as $0=$ negative, $0.5=$ trace of leukocytes, 1 $=$ small amount of leukocytes, $2=$ moderate amount of leukocytes, and $3=$ large amount of leukocytes (Couto et al., 2013). Test readers were blinded to on-farm findings and treatment allocation.

Diagnostic criteria for PVD and ENDO were defined based on the optimal threshold to predict pregnancy status at first service in a subsample of cows that only included untreated cows. The approach to identify optimal thresholds was based on finding the logistic regression model with the lowest Akaike information criteria value after considering all combinations of PVD and ENDO test results (Burnham and Anderson, 1998). In the end, one model was retained for the optimal pair of diagnostic criteria when simultaneously considering vaginal discharge and endometrial cytology results (PVD and ENDO-CYTO). Another model was retained for the optimal pair of diagnostic criteria when considering vaginal discharge and LE results (PVD and ENDO-LE). A complete description of this procedure is reported in the companion paper (Denis-Robichaud and Dubuc, 2015). The optimal diagnostic criteria for PVD in both models was a vaginal discharge score $\geq 4$ (purulent discharge or worse), whereas ENDO-CYTO was optimally defined as a percentage of PMNL $\geq 6 \%$ and ENDO-LE as a LE score $\geq 1$ (small amounts of leukocytes).

Regardless of their reproductive tract health status at $35( \pm 7)$ DIM, cows were randomly assigned (using a predetermined random list within each herd) to receive 1 of 2 treatments: (1) an intrauterine infusion of 500 mg of cephapirin benzathin (Metricure, Merck Animal Health, Kirkland, QC, Canada; treatment group), or (2) no treatment (negative control group). It was impossible to blind producers from treatment allocation because cows in the control group did not receive any treatment. However, producers agreed not to perform any treatment until pregnancy diagnosis after first service was done.

At $35( \pm 7)$ and $49( \pm 7)$ DIM (14 d apart), a blood sample $(10 \mathrm{~mL})$ was drawn from the coccygeal vessels of every enrolled cow into an evacuated tube without additive (Vacutainer; Becton Dickinson, Franklin Lakes, NJ). Samples were kept on ice and allowed to clot. Within $12 \mathrm{~h}$ of collection, samples were centrifuged and serum was harvested and frozen at $-20^{\circ} \mathrm{C}$. These samples were submitted for progesterone mea- surement at the diagnostic laboratory of the Faculté de Médecine Vétérinaire of the Université de Montréal (St-Hyacinthe, QC, Canada) using a sequential competitive immunoassay (Immulite; Siemens, Mississauga, ON, Canada) validated for use in cattle (Martin et al., 2007). The inter- and intraassay coefficients of variation for progesterone were 8.2 and $7.1 \%$, respectively. A cow was considered to have a prolonged anovulation period if both progesterone samples, taken $14 \mathrm{~d}$ apart, had values $<1 \mathrm{ng} / \mathrm{mL}$.

All statistical analyses were performed using SAS 9.3 (SAS Institute Inc., Cary, NC) considering the cow as the unit of interest. Individual cow data such as parity group (first, second or greater), season of calving (winter: January to March; spring: April to June, summer: July to September, fall: October to December), and reproductive and culling events were exported from the computerized record system (DSAHR Inc., SaintHyacinthe, QC, Canada) to Excel (Microsoft Corp., Redmond, WA).

Descriptive statistics were calculated (PROC FREQ and PROC MEANS of SAS). Prevalence of lactation group, season of calving, reproductive tract disease, anovulation status, and pregnancy at first service were calculated overall and stratified by cephapirin treatment groups (PROC FREQ). Interobserver agreement was calculated in a random subsample of 100 results for vaginal discharge, LE, and cytology, and intraobserver agreement was calculated for 100 endometrial cytology slides (Dohoo et al., 2009). Univariable associations (Pearson Chi-squared) between cephapirin treatment and reproductive tract disease, between cephapirin treatment and prolonged anovulation, and between cephapirin treatment and reproductive performance at first service were assessed in mixed logistic regression models accounting for herd clustering (random intercept; PROC GLIMMIX).

Four multivariable mixed logistic regression models (PROC GLIMMIX) were used to quantify the association between cephapirin treatment and pregnancy status at first service. Lactation and season of calving were offered to all models as confounders, and were kept as a fixed effect if their effect on the model estimates was greater than 10\% (Maldonado and Greenland, 1993). All models were forced to include the following variables: prolonged anovulation status, reproductive tract disease, cephapirin treatment, and 2 interaction terms (cephapirin treatment $\times$ reproductive tract disease; cephapirin treatment $x$ anovulation status). All models accounted for the random effect of herd (random intercept). A manual backward elimination procedure was used to build models until $P$-values were $<0.05$ (Dohoo et al., 2009). Cows unaffected by reproductive tract disease were used as the referent for 
the reproductive tract disease variable in all models. A first model was built to assess the effect of cephapirin treatment on reproduction at first service in cows using PVD and ENDO-CYTO as diagnostic tools. A second model was built to assess the effect of cephapirin treatment on reproduction at first service in cows affected by PVD only, ENDO-CYTO only, or both PVD and ENDO-CYTO at the same time. A third model was computed to assess the effect of cephapirin treatment on reproduction at first service in cows using PVD and ENDO-LE as diagnostic tools. A fourth model was built to quantify the effect of cephapirin treatment on reproduction at first service in cows affected by PVD only, ENDO-LE only, or both PVD and ENDO-LE at the same time. For each model, least squares means (LSM) for cephapirin treatment, reproductive tract disease, anovulation status, and for interaction terms (cephapirin treatment $\times$ reproductive tract disease; cephapirin treatment $\times$ anovulation status) were obtained (PROC GLIMMIX). Differences between LSM were calculated using a Tukey-Kramer test. Statistical significance was defined as $P$-values $<0.05$.

\section{RESULTS}

Data from 2,506 Holstein cows were collected during the study period, but LE testing was only performed on 2,135 cows for logistical reasons (material unavailable during the first month of the study in 26 herds). Of all the cows initially enrolled in the study, 235 were excluded because they were culled before pregnancy diagnosis was performed at first service (115 cows in group control; 120 cows in cephapirin treatment group; $P=0.91$ ), and 12 more cows were excluded because they were bred for the first time after 100 DIM ( 5 cows in group control; 7 cows in cephapirin treatment group; $P=0.87$ ). In the end, 2,259 cows were used for analysis during the study period and 1,900 cows were tested for LE. Of all cows enrolled in the study, $31.2 \%$ (n $=705)$ and $68.8 \%(\mathrm{n}=1554)$ were primiparous and multiparous cows, respectively. The distribution of cows within season of calving was $14.2 \%(\mathrm{n}=321)$ for winter, $14.5 \%(\mathrm{n}=328)$ for spring, $32.1 \%(\mathrm{n}=725)$ for summer, and $39.2 \%(\mathrm{n}=885)$ for fall. The overall prevalence of PVD in this study was $18.8 \%(\mathrm{n}=424)$ and ranged from 3.9 to $40.9 \%$ in participating herds. The overall prevalence of ENDO-CYTO was $35.1 \%$ (n $=793$; from 9.3 to $66.2 \%$ in herds) and prevalence of ENDO-LE was $49.2 \%(\mathrm{n}=934$; from 2.3 to $91.2 \%$ in herds). The prevalence of cows unaffected by PVD and ENDO-CYTO was $56.6 \%(\mathrm{n}=1278)$. Out of the 424 cows affected by PVD in this study, 233 cows (55.0\%) also had ENDO-CYTO at the same time. The overall prevalence of prolonged anovulation and pregnancy at first service were $26.9 \%(\mathrm{n}=607)$ and $28.6 \%(\mathrm{n}=646)$, respectively.

Interobserver agreement (kappa) was $0.791 \quad(95 \%$ CI: 0.639-0.931) for vaginal discharge, 0.768 (95\% CI: $0.483-0.935)$ for PMNL percentage, and $0.922(95 \%$ CI: 0.846-0.999) for LE. Intraobserver agreement (kappa) for each observers $(\mathrm{n}=2)$ were $0.754(95 \%$ CI: $0.551-0.822)$ and 0.739 (95\% CI: $0.486-0.898)$ for PMNL percentage.

Univariable associations between cephapirin treatment and various variables such as reproductive tract disease, anovulation status, and pregnancy at first service are reported in Table 1. In total, $51.1 \%(\mathrm{n}=1,154)$ were treated with cephapirin in the study, whereas 48.9\% ( $\mathrm{n}=1,105)$ were not treated (negative control group; $P=0.13$ ). In the subsample of cows tested for ENDO-LE (1,900 cows), 50.5\% $(\mathrm{n}=960)$ were treated with cephapirin in the study, whereas $49.5 \%(\mathrm{n}=940)$ were not treated (negative control group; $P=0.43$ ).

Four final mixed multivariable logistic regression models were built to assess the association between cephapirin treatment and first-service pregnancy risk when considering different reproductive tract disease diagnosis approaches. The first model was built to evaluate this association when accounting for PVD and ENDO-CYTO (Table $2 ; \mathrm{n}=2,259$ cows). The interpretation of this model can be difficult because multiple 2 -way interaction terms are present. To facilitate the interpretation, LSM of first-service pregnancy risk from this model stratified by cephapirin treatment status are presented in Figure 1. This figure shows that intrauterine cephapirin treatment increased first-service pregnancy risk in cows affected by PVD (no treatment: 14.5\% ; cephapirin: $30.9 \% ; P<0.01)$ and ENDO-CYTO (no treatment: $16.6 \%$; cephapirin: $25.9 \% ; P<0.01$ ) but not in unaffected cows (no treatment: $34.5 \%$; cephapirin: $31.8 \% ; P=0.54)$. Figure 1 also shows that cephapirin treatment increased first-service pregnancy risk in ovular cows (no treatment: $22.7 \%$; cephapirin: $34.1 \%$; $P$ $<0.01$ ) but not in anovular cows (no treatment: $21.0 \%$; cephapirin: $26.5 \% ; P=0.10$ ).

Least squares means from the second model $(\mathrm{n}=$ 2,259 cows) show that intrauterine cephapirin treatment was associated with an increased first-service pregnancy risk in cows only affected by PVD (no treatment: $14.2 \%$; cephapirin: $30.6 \% ; P<0.01$ ), in cows only affected by ENDO-CYTO (no treatment: 16.1\%; cephapirin: $26.3 \%$; $P<0.01$ ), and in cows affected by both PVD and ENDO-CYTO at the same time (no treatment: $8.7 \%$; cephapirin: $23.4 \% ; P=0.03$ ) but not in cows unaffected by reproductive tract disease (no treatment: $32.6 \%$; cephapirin: $31.5 \% ; P=0.86$ )

The third model was built to account for PVD and ENDO-LE (Table $3 ; \mathrm{n}=1,900$ cows). Figure 2 presents 
Table 1. Univariable associations between intrauterine cephapirin treatment at $35( \pm 7)$ DIM and reproductive tract disease status, anovulation status, and pregnancy at first service in Holstein dairy cows enrolled in a randomized clinical trial

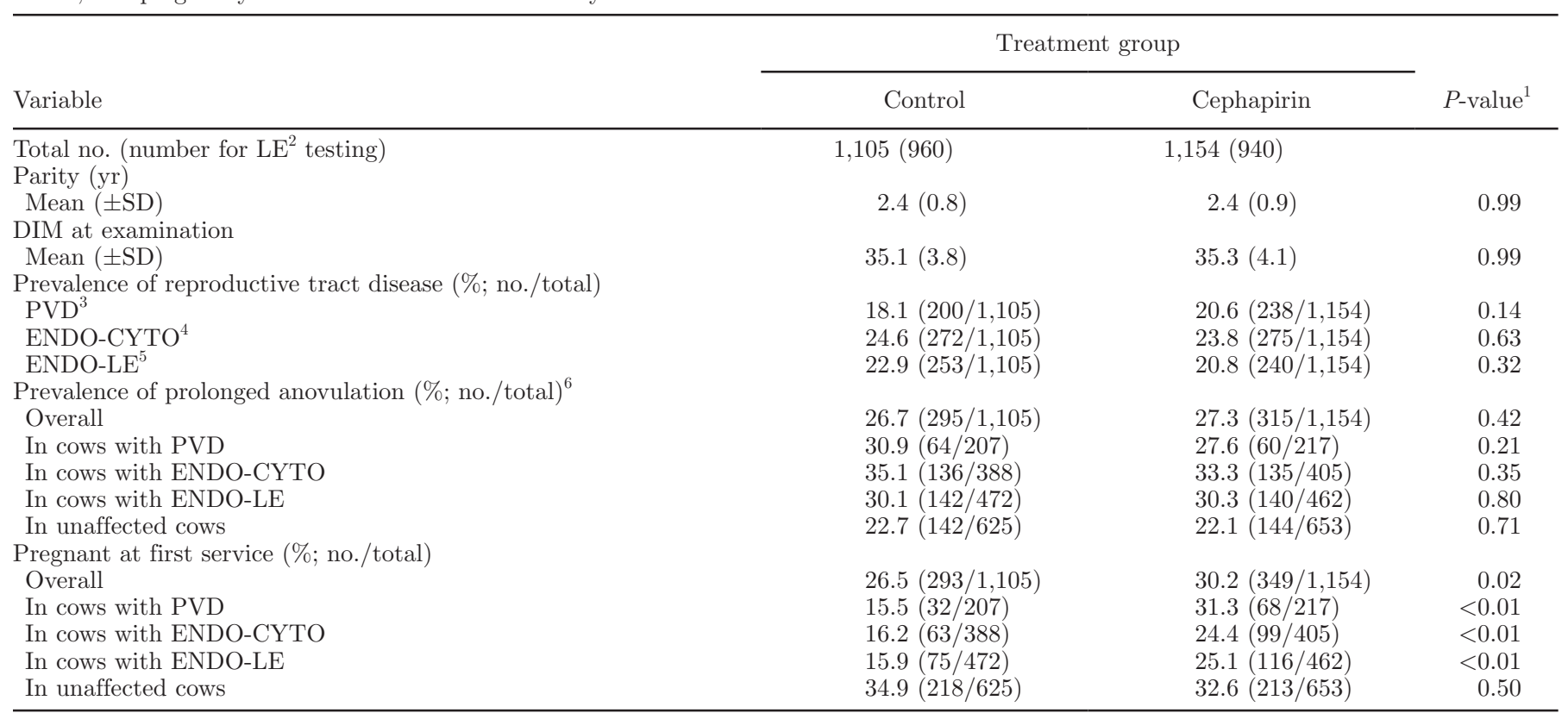

\footnotetext{
${ }^{1}$ Adjusted for herd clustering (random intercept).

${ }^{2}$ Leukocyte esterase.

${ }^{3}$ Purulent vaginal discharge defined as PVD or worse $(\geq 4)$ using the Metricheck technique (Simcro, Hamilton, New Zealand).

${ }^{4}$ Endometritis defined as $\geq 6 \%$ PMNL at endometrial cytology using the cytobrush technique.

${ }^{5}$ Endometritis defined as small amounts of leukocyte or worse $(\geq 1)$ using the leukocyte esterase technique.

${ }^{6}$ Prolonged anovulation defined as serum progesterone $<1 \mathrm{ng} / \mathrm{mL}$ at 35 and $49( \pm 7)$ DIM.
}

Table 2. Final mixed logistic regression model of first-service pregnancy risk, accounting for the random effect of herd, in 2,259 Holstein dairy cows from 28 herds enrolled in a clinical trial investigating the effect of intrauterine cephapirin treatment for reproductive tract disease based on vaginal discharge and endometrial cytology at $35( \pm 7)$ DIM

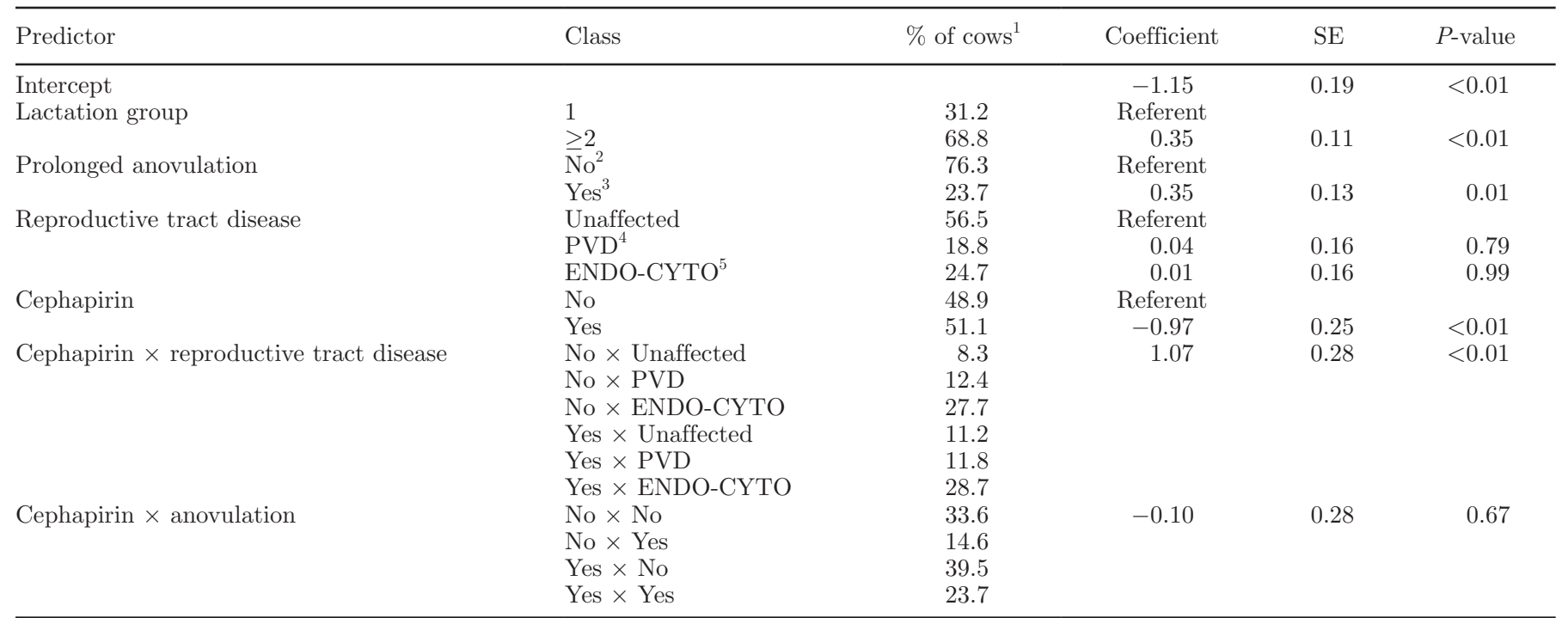

${ }^{1}$ Proportion of cows in each category of predictor; within each predictor the sum is $100 \%$.

${ }^{2}$ Serum progesterone $\geq 1 \mathrm{ng} / \mathrm{mL}$ at 35 or $49( \pm 7)$ DIM or both.

${ }^{3}$ Serum progesterone $<1 \mathrm{ng} / \mathrm{mL}$ at 35 and $49( \pm 7)$ DIM.

${ }^{4}$ Purulent vaginal discharge defined as PVD or worse $(\geq 4)$ using the Metricheck technique (Simcro, Hamilton, New Zealand).

${ }^{5}$ Endometritis defined as $\geq 6 \%$ PMNL at endometrial cytology using the cytobrush technique. 
LSM from this model. This figure illustrates that intrauterine cephapirin treatment increased first-service pregnancy risk in cows affected by PVD (no treatment: 14.2\% ; cephapirin: $30.4 \% ; P<0.01$ ) and ENDO-LE (no treatment: $16.6 \%$; cephapirin: $29.9 \% ; P<0.01$ ) but not in unaffected cows (no treatment: $32.1 \%$; cephapirin: $30.6 \% ; P=0.73)$. This figure also shows that cephapirin treatment increased first-service pregnancy risk in ovular cows (no treatment: 25.5\%; cephapirin: $33.9 \% ; P$ $<0.01$ ) but not in anovular cows (no treatment: $21.4 \%$; cephapirin: $23.8 \% ; P=0.81)$.

From the fourth model ( $\mathrm{n}=1,900$ cows), LSM show an increased first-service pregnancy risk in cows only affected by PVD (no treatment: 14.8\%; cephapirin: $30.1 \% ; P<0.01$ ), in cows only affected by ENDO-LE (no treatment: $15.9 \%$; cephapirin: $28.9 \%$; $P<0.01$ ), and in cows affected by both PVD and ENDO-LE (no treatment: $9.8 \%$; cephapirin: $23.1 \% ; P=0.04$ ), but not in cows unaffected by reproductive tract disease (no treatment: $31.9 \%$; cephapirin: $30.6 \% ; P=0.96$ ).

\section{DISCUSSION}

This study is one of the first to quantify the effect of intrauterine cephapirin therapy in postpartum dairy cows when considering diagnosis of PVD and ENDO simultaneously at $35( \pm 7)$ DIM. Such an approach allows quantification of the overall effect of treatment on the subsequent reproductive performance of dairy cows affected by reproductive tract disease. As expected at the start of the study, intrauterine cephapirin therapy had a positive effect on first-service pregnancy risk and this effect was modulated by reproductive tract health status. Cows affected by PVD, ENDO-CYTO, or ENDO-LE had improved first-service pregnancy risk compared with untreated cows (Figures 1 and 2). For PVD, the magnitude of this improvement was 16 percentage points on first-service pregnancy risk, which is consistent with previous studies reporting a similar benefit of using cephapirin therapy in cows affected by PVD (LeBlanc et al., 2002b; Runciman et al., 2008). For ENDO-CYTO and ENDO-LE, the improvement on first-service pregnancy risk was 9 and 13 percentage points, respectively. A previous study reported a similar benefit of cephapirin treatment in cows with ENDO-CYTO (15 percentage points; Kasimanickam et al., 2005). Treatment benefit for cows with ENDO-LE as shown in the present study is novel and has not been reported previously. This finding supports the increasing interest of diagnosing ENDO-LE on farms because this technique can provide cow-side results that can lead to immediate cow treatment when needed (DenisRobichaud and Dubuc, 2015). For cows having both PVD and ENDO-CYTO at the same time, treatment benefit on first-service pregnancy risk was 14 percentage points, whereas it was 13 percentage points for the combination of PVD and ENDO-LE. Such treatment benefit in cows simultaneously diagnosed with PVD

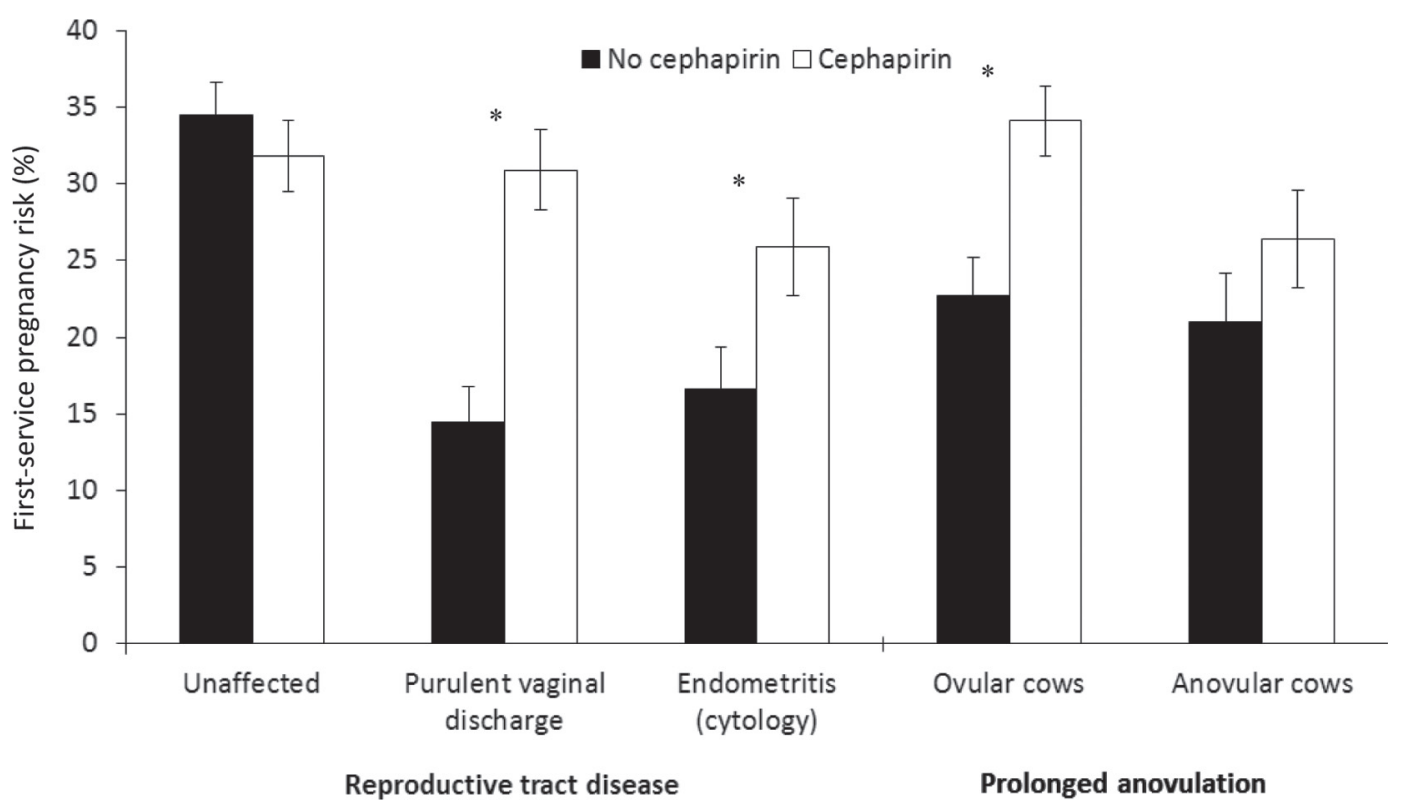

Figure 1. Least squares means $( \pm$ SEM) of intrauterine cephapirin treatment at $35( \pm 7)$ DIM on first-service pregnancy risk stratified by reproductive tract disease [unaffected, purulent vaginal discharge diagnosed by Metricheck technique (Simcro, Hamilton, New Zealand), or cytological endometritis diagnosed by endometrial cytobrush technique] and by prolonged anovulation [serum progesterone $<1 \mathrm{ng} / \mathrm{mL}$ at 35 and 49 $( \pm 7)$ DIM] in 2,259 Holstein cows enrolled in a randomized clinical trial. *Significant effect of treatment within strata $(P<0.05)$. 


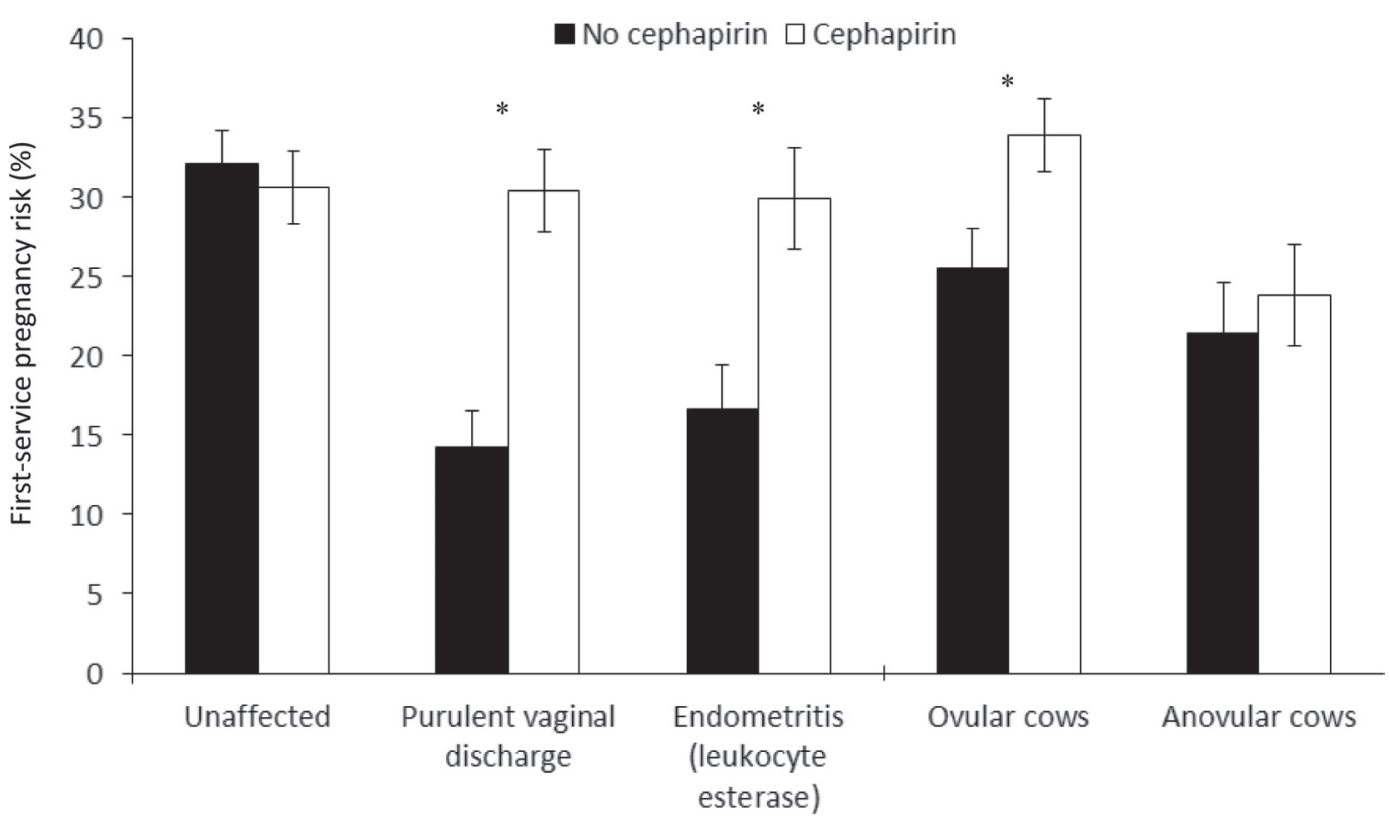

Reproductive tract disease

Prolonged anovulation

Figure 2. Least squares means $( \pm$ SEM) of intrauterine cephapirin treatment at $35( \pm 7)$ DIM on first-service pregnancy risk stratified by reproductive tract disease [unaffected, purulent vaginal discharge diagnosed by Metricheck technique (Simcro, Hamilton, New Zealand), or cytological endometritis diagnosed by endometrial leukocyte esterase technique] and by prolonged anovulation [serum progesterone $<1 \mathrm{ng} / \mathrm{mL}$ at 35 and $49( \pm 7) \mathrm{DIM}]$ in 1,900 Holstein cows enrolled in a randomized clinical trial. ${ }^{*}$ Significant effect of treatment within strata $(P<0.05)$.

Table 3. Final mixed logistic regression model of first-service pregnancy risk, accounting for the random effect of herd, in 1,900 Holstein dairy cows from 28 herds enrolled in a clinical trial investigating the effect of intrauterine cephapirin treatment for reproductive tract disease based on vaginal discharge and leukocyte esterase at $35( \pm 7)$ DIM

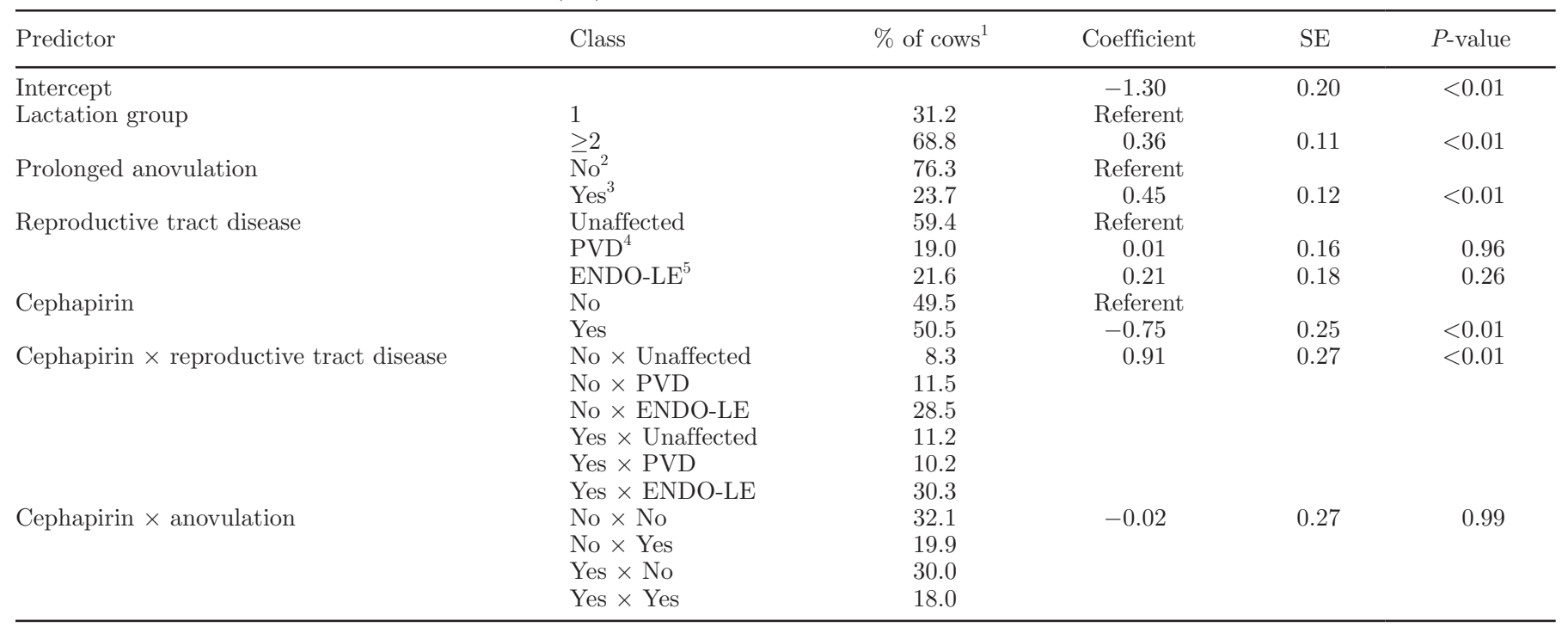

${ }^{1}$ Proportion of cows in each category of predictor; within each predictor, the sum is $100 \%$.

${ }^{2}$ Serum progesterone $\geq 1 \mathrm{ng} / \mathrm{mL}$ at 35 or $49( \pm 7)$ DIM or both.

${ }^{3}$ Serum progesterone $<1 \mathrm{ng} / \mathrm{mL}$ at 35 and $49( \pm 7)$ DIM.

${ }^{4}$ Purulent vaginal discharge defined as PVD or worse $(\geq 4)$ using the Metricheck technique (Simcro, Hamilton, New Zealand).

${ }^{5}$ Endometritis defined as endometrial leukocyte esterase score $\geq 1$ (small amounts of leukocytes). 
and ENDO-CYTO or with PVD and ENDO-LE has never been reported before. Not surprisingly, cephapirin therapy did not improve first-service reproductive performance in cows unaffected by reproductive tract disease, which is consistent with another report (Kasimanickam et al., 2005).

A goal of the present study was to determine whether prolonged postpartum anovulation influences the magnitude of the benefit of cephapirin treatment. To address this objective, the interaction term cephapirin treatment $\times$ anovulation status was forced in all multivariable models. Not surprisingly, the interaction term was not significant in final models as the sample size targeted for this study was focused on finding a significant effect of treatment in cows with reproductive tract disease. A sufficient sample size for this objective would have been around 10,000 cows based on a priori calculations. Thus, we expected that the statistical power would be insufficient for this 2-way interaction term in all models but it was forced to calculate LSM. Therefore, differences between LSM from this 2-way interaction term were used to determine if the effect of cephapirin treatment was significant. As expected at the start of the study, the benefit of treating reproductive tract disease cows with cephapirin was influenced by postpartum anovulation status. More specifically, cephapirin treatment increased first-service pregnancy risk of ovular cows by 8 to 12 percentage points, whereas it increased first-service pregnancy risk in anovular cows by only 1 to 5 percentage points, which was not statistically significant. Interestingly, LeBlanc et al. (2002b) showed that intrauterine cephapirin treatment had a smaller effect on reproductive performance when no corpus luteum was palpable in cows with PVD at 27 to 33 DIM (as a proxy for prolonged anovulation) compared with when cows had a palpable corpus luteum. Results from LeBlanc et al. (2002b) and the present study are consistent and suggest that anovular cows obtain less benefit from cephapirin therapy than ovular cows. Considering these results, it must be noted that categorization of prolonged anovulation in these data was across the entire population of cows and irrespective of reproductive tract disease status. Unfortunately, our sample size was insufficient to test whether intrauterine cephapirin treatment of anovular cows with reproductive tract disease was effective. However, these results suggest that the benefit of implementing a systematic intrauterine cephapirin treatment strategy for cows with reproductive tract disease in herds with high or low incidence of anovulation may be variable and needs to be clarified. It also remains unclear at this point why ovular cows had a greater magnitude of benefit from cephapirin treatment than did anovular cows. Logically, intrauterine antibiotic treatment should re- duce the uterine bacterial population, which otherwise would delay the process of uterine involution, as stated by LeBlanc et al. (2002b). A reduction in the bacterial population could reduce the presence of inflammation and improve subsequent reproductive performance. It is known that the presence of some bacteria in the uterus during the postpartum period can delay the resumption of ovarian function (Sheldon et al., 2009). Anovular cows could be infected by bacteria on which cephapirin would have a reduced or absent antibiotic effect. Future research should focus on identifying uterine bacteria in ovular and anovular cows. Another explanation for these results could be that the benefit of cephapirin treatment would be potentiated by evacuation of the uterine contents during estrus periods. Such uterine evacuation after cephapirin treatment could reduce the presence of inflammatory material in the uterus and subsequently lead to better treatment efficacy in ovular cows. Therefore, anovular cows could somehow benefit from a reduction in the bacterial population but might not evacuate uterine contents after treatment. This situation could reduce the benefit of cephapirin treatment as inflammatory material would remain inside the uterus and interfere with embryo development (Hill and Gilbert, 2008). Further research is needed to better understand how prolonged anovulation influences the benefit of intrauterine treatment.

\section{CONCLUSIONS}

The use of intrauterine cephapirin treatment improved first-service pregnancy risk in cows with PVD, ENDO-CYTO, or ENDO-LE, but not in cows unaffected by reproductive tract disease. The use of cephapirin treatment in cows affected by reproductive tract disease and prolonged postpartum anovulation only increased first-service pregnancy risk by 1 to 5 percentage points, whereas it was increased by 8 to 12 percentage points in ovular cows with similar reproductive tract disease. Further research should clarify how prolonged anovulation potentiates the effect of intrauterine cephapirin treatment on subsequent reproduction in dairy cows.

\section{ACKNOWLEDGMENTS}

This project was financially supported by Merck Animal Health (Montréal, QC, Canada). José DenisRobichaud received scholarships from Novalait (Longueuil, QC, Canada), Fonds de recherche du Québec en nature et technologie (FRQNT; Québec, QC, Canada), and Conseil Canadien de recherche en sciences naturelles et génie (CRSNG; Ottawa, ON, Canada) during her graduate studies. Financial support from Fonds de recherche clinique Zoetis (St-Hyacinthe, QC, Canada) 
is also acknowledged. The authors are grateful to the participating farmers and the technical support staff.

\section{REFERENCES}

Burnham, K. P., and D. R. Anderson. 1998. Model Selection and Multimodel Inference. 2nd ed. Springer, New York, NY.

Cheong, S. H., D. V. Nydam, K. N. Galvao, B. M. Crosier, A. Ricci, L. S. Caixeta, R. B. Sper, M. Fraga, and R. O. Gilbert. 2012. Use of reagent test strips for diagnosis of endometritis in dairy cows. Theriogenology 77:858-864.

Couto, G. B., D. H. Vaillancourt, and R. C. Lefebvre. 2013. Comparison of a leukocyte esterase test with endometrial cytology for diagnosis of subclinical endometritis in postpartum dairy cows. Theriogenology 79:103-107.

Denis-Robichaud, J., and J. Dubuc. 2015. Determination of optimal diagnostic criteria for purulent vaginal discharge and cytological endometritis in dairy cows. J. Dairy Sci. 98:6848-6855. http:// dx.doi.org/10.3168/jds.2014-9120.

Dohoo, I. R., S. W. Martin, and H. Stryhn. 2009. Veterinary Epidemiologic Research. 2nd ed. VER Inc., Charlottetown, PEI, Canada.

Dubuc, J., T. F. Duffield, K. E. Leslie, J. S. Walton, and S. J. LeBlanc. 2010. Definitions and diagnosis of postpartum endometritis in dairy cows. J. Dairy Sci. 93:5225-5233.

Dubuc, J., T. F. Duffield, K. E. Leslie, J. S. Walton, and S. J. LeBlanc. 2012. Risk factors and effects of postpartum anovulation in dairy cows. J. Dairy Sci. 95:1845-1854.

Galvão, K. N., M. Frajblat, W. R. Butler, S. B. Brittin, C. L. Guard, and R. O. Gilbert. 2010. Effect of early postpartum ovulation on fertility in dairy cows. Reprod. Domest. Anim. 45:e207-e211.

Gilbert, R. O., S. T. Shin, C. L. Guard, H. N. Erb, and M. Frajblat. 2005. Prevalence of endometritis and its effects on reproductive performance of dairy cows. Theriogenology 64:1879-1888.

Hill, J., and R. Gilbert. 2008. Reduced quality of bovine embryos cultured in media conditioned by exposure to an inflamed endometrium. Aust. Vet. J. 86:312-316.

Kasimanickam, R., T. F. Duffield, R. A. Foster, C. J. Gartley, K. E. Leslie, J. S. Walton, and W. H. Johnson. 2004. Endometrial cytology and ultrasonography for the detection of subclinical endometritis in postpartum dairy cows. Theriogenology 62:9-23.
Kasimanickam, R., T. F. Duffield, R. A. Foster, C. J. Gartley, K. E. Leslie, J. S. Walton, and W. H. Johnson. 2005. The effect of a single administration of cephapirin or cloprostenol on the reproductive performance of dairy cows with subclinical endometritis. Theriogenology 63:818-830.

LeBlanc, S. J., T. F. Duffield, K. E. Leslie, K. G. Bateman, G. P. Keefe, J. S. Walton, and W. H. Johnson. 2002a. Defining and diagnosing postpartum clinical endometritis and its impact on reproductive performance in dairy cows. J. Dairy Sci. 85:2223-2236.

LeBlanc, S. J., T. F. Duffield, K. E. Leslie, K. G. Bateman, G. P. Keefe, J. S. Walton, and W. H. Johnson. 2002b. The effect of treatment of clinical endometritis on reproductive performance in dairy cows. J. Dairy Sci. 85:2237-2249.

Maldonado, G., and S. Greenland. 1993. Simulation study of confounder-selection strategies. Am. J. Epidemiol. 138:923-936.

Martin, J. L., K. A. Vonnahme, D. C. Adams, G. P. Lardy, and R. N. Funston. 2007. Effects ofdam nutrition on growth and reproductive performance of heifer calves. J. Anim. Sci. 85:841-847.

McDougall, S., R. Macaulay, and C. Compton. 2007. Association between endometritis diagnosis using a novel intravaginal device and reproductive performance in dairy cattle. Anim. Reprod. Sci. 99:9-23.

Runciman, D. J., G. A. Anderson, and J. Malmo. 2009. Comparison of two methods of detecting purulent vaginal discharge in postpartum dairy cows and effect of intrauterine cephapirin on reproductive performance. Aust. Vet. J. 87:369-378.

Runciman, D. J., G. A. Anderson, J. Malmo, and G. M. Davis. 2008. Effect of intrauterine treatment with cephapirin on the reproductive performance of seasonally calving dairy cows at risk of endometritis following periparturient disease. Aust. Vet. J. 86:250-258.

Sheldon, I. M., J. Cronin, L. Goetze, G. Donofrio, and H.-J. Schuberth. 2009. Defining postpartum uterine disease and the mechanisms of infection and immunity in the female reproductive tract in cattle. Biol. Reprod. 81:1025-1032.

Vieira-Neto, A., R. O. Gilbert, W. R. Butler, J. E. P. Santos, E. S. Ribeiro, M. M. Vercouteren, R. G. Bruno, J. H. J. Bittar, and K. N. Galvão. 2014. Individual and combined effects of anovulation and cytological endometritis on the reproductive performance of dairy cows. J. Dairy Sci. 97:5415-5425.

Walsh, R. B., D. F. Kelton, T. F. Duffield, K. E. Leslie, J. S. Walton, and S. J. LeBlanc. 2007. Prevalence and risk factors for postpartum anovulatory condition in dairy cows. J. Dairy Sci. 90:315-324. 